\title{
Exploring Information Quality in Accounting Information Systems Adoption
}

\author{
Manirath Wongsim and Jing Gao
}

School of Computer and Information Science, University of South Australia, Mawson Lakes, Australia

\begin{abstract}
Information Quality (IQ) Management plays a vital role in the process of Accounting Information Systems (AIS) adoption. IQ is emerging as a well-known business problem in modern organisations. Specifically, the level of information quality is critical for all accounting processes, and has a significant impact on business decision-making. It must be noted that modern organisations rely heavily on the use of accounting information systems for their accounting processes. There is a growing need for research to provide insights into issues and solutions related to IQ in AIS adoption. This research aims to explore ways of managing information quality and AIS adoption to investigate the relationship between the IQ issues and AIS adoption process. This study has led to the development of a framework to guide the organisations on implementing an adequate IQ management approach during the system adoption process. This research was done on 44 respondents at ten organisations within manufacturing firms in Thailand. The findings of the research's empirical evidence suggest that IQ dimensions in AIS adoption provide assistance in all processes of decision making. This research provides empirical evidence that information quality of AIS adoption affect decision making and suggests that these variables should be considered in adopting AIS in order to improve the effectiveness of AIS.
\end{abstract}

Keywords: Information Quality, Information Quality Dimensions, Accounting Information Systems, Accounting Information System Adoption.

\section{Introduction}

Nowadays, information is one of the main resources used and applied in organisations. Information development is essential for improving or developing new contexts to support management, strategy, and decision making (Lee, Strong et al. 2002; Michnik and Lo 2009; Salaün and Flores 2001). Furthermore, management information is important in organisations as it requires quality information, to improve the efficiency and effectiveness of their operations for higher profitability and increased productivity. For significant business decision-making, Information
Quality (IQ) has become an important consideration for any organisation that wants to perform a variety of tasks well. Information Quality refers to the capability of data to be fit for use.

There is a strong evidence that IQ issues have become a critical concern for organisations (Lee, Strong et al. 2002; Michnik and Lo 2009). Salaun and Flores (2001) indicate that, currently, customers require good quality information which is basic to the requirements of business activity and lead to high quality work performance in the partnership between supplier and consumer. According to Lee,

Copyright (C) 2011 Manirath Wongsim and Jing Gao. This is an open access article distributed under the Creative Commons Attribution License unported 3.0, which permits unrestricted use, distribution, and reproduction in any medium, provided that original work is properly cited. Contact author: Manirath Wongsim e-maill: Manirath.Wongsim@postgrads.unisa.edu.au. 
Strong et al (2002), the growth of data warehouses has increased the need for quality data in order for organisations to perform well, obtain competitive advantage, and survive in today's global economy. Thus, data management is important in organisations, in order to support and develop different departments in corporations by enabling work processes of all sorts, as well as decisionmaking.

In particular, accounting is essential in making economic decisions. Furthermore, accounting and management decisionmaking is dependent on the fit of the Accounting Information Systems (AIS) with the organisation's requirements. Therefore, organisations must pay attention to the efficiency of their accounting information systems. In order to implement AIS successfully, it is important to address the quality of information adoption, to manage all the processes of accounting systems. Thus, this research intends to study this perspective of IQ management in AIS adoption.

\section{Background}

Information quality problems can impact on operations, increase costs and lower worker job-satisfaction, while increasing customer dissatisfaction (Redman 1998). In a modern world, information quality is potent in that it directs the business's future. This is because good information quality can lead to success while poor information quality can lead to failure of the business (Bovee 2004; Redman 1998; Redman 2008). Consequently, information quality criteria have become important considerations for any organisation that wants to carry out a variety of processes well.

In particular, accounting and management decision-making are concerned with the appropriateness of the AIS for the organisation's requirements for information communication and control (Gordon and Miller 1976; McLaney and Atrill 2005). The argument behind this finding is that accounting information systems often lack high-quality data.
Likewise, Ismail and King (2005) find that organisations may lack knowledge and the vision to incorporate accounting information systems; additionally, there are still problems in the process of accounting implementation. However, business needs to be seen as a system using accounting information well, requiring quality data in organisations to perform well, obtain competitive advantage, and survive in today's global economy. These are all critical to a company in order to organise, manage and operate processes in all sections. Furthermore, organisational structure is important to improving or adopting AIS systems. A well-managed, well-designed accounting system can improve work performance and increase the efficiency of activities in accounting responsibility.

Findings from the literature indicate that an AIS is a specific software application and management process. Kaplan (1998) indicates that enterprises should operate management accounting outside the ERP system because the same system cannot provide information for financial accounting. What's more, Malmi (2001) and Scapens and Jazayeri (2003) find that the relationship between ERP systems and management accounting techniques have not changed significantly. However, while ERP systems are considered to be important data sources for most new accounting practises, they are not an incentive for accounting techniques and system adoption. The characteristics of accounting techniques are different in a number of elements. Moreover, Rom and Rohde (2007) indicate that data integration in accounting should be studied more narrowly (Rom and Rohde 2007). Other authors (e.g. Davila, Foster et al, 2004; Naomi and Kevin, 2007; Ismail, 2009; Romney and Steinbart, 2009) state that within organisations there must be attention given to the accounting standards and laws of each country.

Recently, when adopting AIS, some organisations used AIS vendors for adopting accounting systems developed by the software vendors for the organisations who want to adopt their solutions. Other 
organisation adopted generic frameworks developed by COBIT, ITIL, and SDLC as guidelines on how to select and adopt AIS systems, even though not specific for AIS adoption.

Most of the research concerning AIS has focused on the management of internal controls, design of an accounting information system and auditing (Choe 2004; Nicolaou 2000). Few studies have attempted to understand how to choose and use (adopt) AIS systems well, in organisations, to meet all IQ requirements. In order to ensure information quality in AIS adoption, it is important to understand the underlying appropriate IQ criteria specifically for AIS adoption. However, no standard definition exists today; although there have been some studies of qualitative characteristics in accounting quality management, such as FASB, IASB, AARF, and SAC3. Some of the IQ literature also addresses the critical points and steps for adopting IQ systems.
Interestingly, IQ management specific to AIS adoption is a new area; there is a growing need for research to provide insight into issues and solutions related to IQ management in AIS adoption. A number of generic IQ frameworks have been proposed in the literature, but none of them has actually looked into the area of AIS adoption. There is a lack of knowledge and of a standards framework for information quality management in accounting information systems adoption that can assist organisations to ensure and improve accounting information quality. Thus, this research tries to develop an adequate framework to provide such guidance.The framework is developed based upon the existing literature review and multiple case studies. The framework has been designed to illustrate IQ issues in AIS adoption. It also attempts to identify the critical success factors that organisations should focus on, to ensure IQ during the systems adoption process.

\section{Framework for Information Quality Management in Accounting Information Systems Adoption}

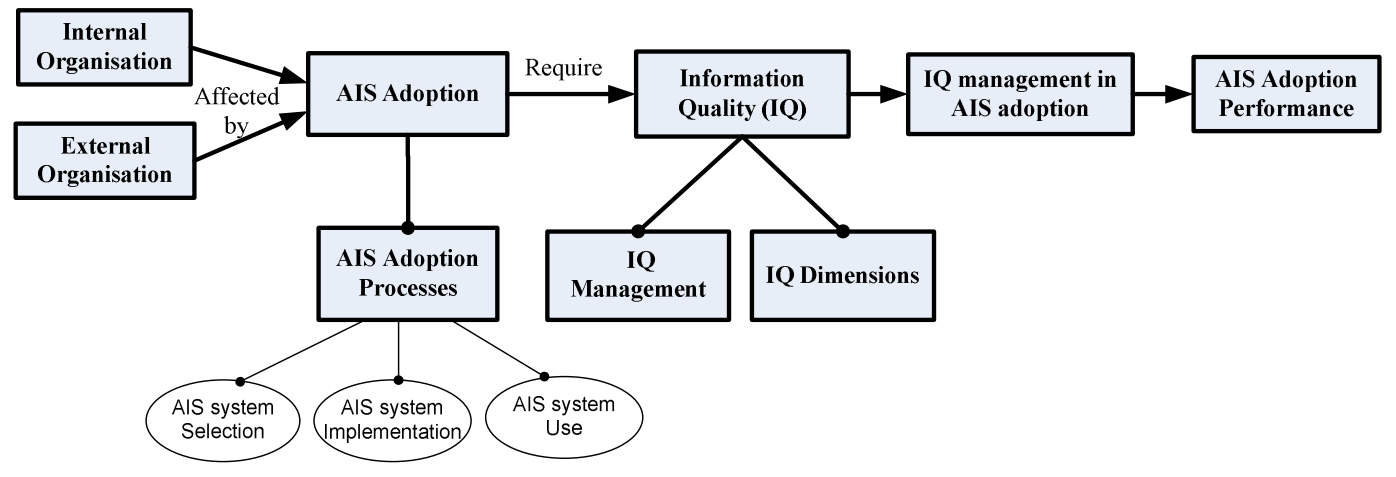

Fig 1. IQ Management in AIS Adoption Framework (Source: Developed by the authors)

The research framework for this study is presented in Fig 1. The framework posits that accounting information systems adoption is affected by internal and external organisations and also requires quality information in order to function effectively. Moreover, accounting and management decision making are concerned with the appropriateness of the AIS for the organisation's requirements for information communication and control. In order to adopt AIS successfully, it is important to consider the quality of the system and the quality of information used throughout the adoption process (Delone and McLean 2003; Nelson and Todd 2005). Likewise, information quality dimensions influence the advantage of AIS adoption. This is because information quality dimensions utilised in AIS adoption can help organisations to understand the requirements for delivering high quality information. Furthermore, accounting systems adoption requires quality information in order to function effectively, where the level of information quality is 
critical for all accounting system processes. Information quality dimensions are relevant to all data management processes adopted by an organisation. Thus, organisations need to apply information criteria to organize and control all stages of AIS and AIS adoption. This framework links IQ management efforts to AIS adoption performance. The framework is developed based upon the existing literature and the exploratory multiple case study, discussed in detail in the next sections.

\section{Research Methodology}

This research used qualitative, interpretive evidence. Interpretive research often involves using qualitative methods from which to develop awareness gained from the data collection, and analyses the research process (Avison and Myers 2002; Orlikowski and Baroudi 1991). In this study, collecting relevant information was done by conducting interviews following initial exploratory work. Literature reviews were used together with a conceptual study research method in order to develop interview questions.

Furthermore, this study used case studies in ten organisations as confirmatory evidence. The selection of cases in this study was purposefully carried out in order to achieve theoretical and literal replication. Cases were selected on the basis of three dimensions: industry type, and the size and type of organisation. Regarding the first dimension, there are different types of business - agricultural, financial, industrial, education and government. The second dimension relates to organisation sectors, consisting of public and private groups. The third dimension focuses on the size of various organisations, especially large corporations and SMEs. The selected organisations are from Thailand but enable the dimensions to be addressed.

Case studies were used to provide useful insights into the nature of IQ issues when adopting AIS. This study used in-depth interviews to collect information as well as involving semi-structured interviews and unstructured interviews with stakeholders such as:
- Data producers who create, collect and monitor information for AIS.

- Data auditors who record, classify, report and interpret financial information.

- Data analysts who analyse, design, develop and operate AIS adoption.

- Data users who access and operate AIS in their work activities.

- Data managers who are responsible for managing and controlling information and information quality in AIS adoption.

Moreover, data collection sources also included relevant documents, such as position descriptions, policy manuals, organisational charts, service records, and annual reports. The purpose of the case studies was to investigate what was an appropriate IQ issue associated with AIS adoption and how best to choose and use an AIS adoption in organisations, considering factors before and during the adoption of an AIS. Moreover, the qualitative data analysis methods used included pattern-matching, content analysis, and cross-case synthesis.

\section{Research Finding}

\section{IQ Dimensions in AIS Adoption}

In this research, IQ dimensions are identified as relevance, reliability, comparability, understandability, availability, effectiveness, efficiency, confidentiality, accessibility, integrity, compliance, accuracy, objectivity, security, completeness, and timeliness, as identified from the literature and business requirements from information in the multiple case studies. These information quality dimensions are relevant to all data management processes adopted by organisations, as show in Fig 2. The results of IQ dimensions in AIS adoption, all variables in this study, were measured by in-depth interviews. Furthermore, the research summarises the scores given by different stakeholders in Case A to Case J (the ten organisations). 


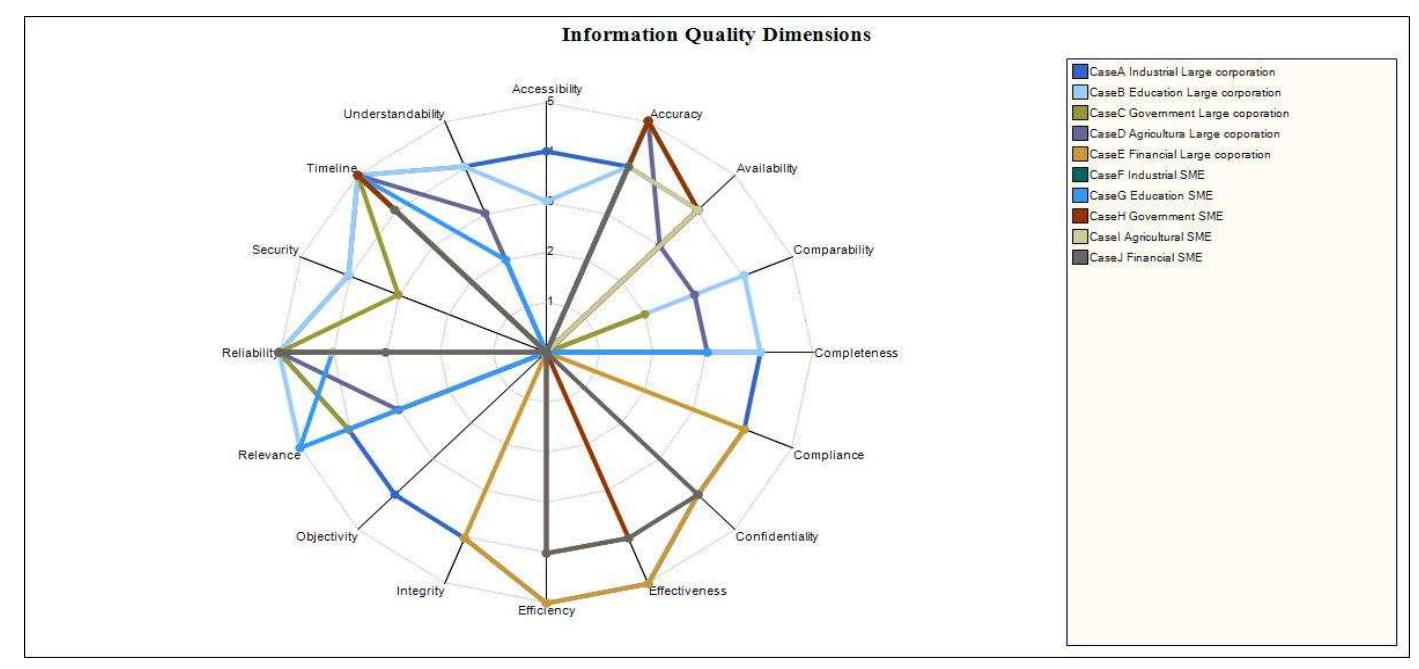

Fig 2. Result of IQ Dimension form Multiple Case Studies (Source: Developed by the authors)

Legend: 1, 2, 3, 4, 5 = Rating of the importance [never=1, rarely=2, sometime=3, often=4, always $=5]$

Fig 2 presents the results of IQ dimensions in AIS adoption from sixteen dimensions among the 44 respondents. Respondents were asked to indicate on a scale of five choices consisting of never agree, rarely agree, sometime agree, often agree, and always agree. Thai listed organisations have score of 5.00 for IQ dimensions such as Accuracy, Effectiveness, Efficiency, Relevance, Reliability and Timeline; the firms have a score of 4.00 for all IQ dimensions; a score of 3.00 for IQ dimensions including Accessibility, Availability, Comparability, Completeness, Relevance, Reliability, Security, and Understandability; a score of 2.00 for IQ dimensions of Comparability and Understandability; a score of less than 2.00 for any IQ dimension was not revealed by the results.

One of the interviewees illustrated the significance of positive relationships between the performance of an AIS adoption and IQ dimensions in the AIS system. The CEO noted that:

"I think organisations need to satisfy the quality, reliability and security requirements for our information, as for all assets. We need for available IT resources, including applications, information, infrastructure and people to drive business goals. In ours organisation identifies to satisfy business goals by used information quality dimension to control accounting information systems and AIS adoption. We have been described by information dimension including Accessibility, Accuracy, Availability, Completeness, Compliance, Confidentiality, Effectiveness, Efficiency, Integrity, Objectivity, Relevance, Reliability, Security, Timeline and Understandability in all adoption process".

CEO (Company A)

Company A used information quality criteria to successfully adopt AIS. They used information criteria to control all stages of the AIS adoption process for checking the system. Organisation A aimed to define requirements for IQ criteria, and then applied requirements management and requirements analysis to control and improve all processes within AIS adoption. Moreover, they are concerned about the root causes of IQ problems and aim to determine the impact of poor IQ. Most importantly, the project manager is responsible for all IQ management efforts to improve quality of information in decision making for the acquired AIS system. This company needs to be seen as effectively adopting AIS, meeting the required quality of accounting information. 
In addition, the IT manager in company B believes that the AIS are important in helping organisations to make profits. Company B was also concerned to identify that IQ dimensions help to ensure alignment to business requirements. As one of the interviewees indicated:

"In our organisation, we have been information quality dimensions to control work processes refer to as business process and AIS process for information quality such as Reliability, Confidentiality, Accuracy, Availability, Integrity, Compliance, Accessibility, Security, Comprehensiveness, Relevance, Effectiveness, Efficiency, Timeline, Comparability, Understandability. $I Q$ dimensions can help organisation to managing and controlling information to satisfy business objective. What is more, the company would like to conduct the IQ dimension checks before moving accounting data into the new system. We have been satisfying AIS system and can help ours a lot to operate work performances".

\section{IT Manager (Company B)}

Company B believes that IQ dimensions help to ensure configuration to business requirements. Especially, they have to check the IQ dimensions during the change-over process to make sure data is moved into the new system with a high level of information quality. Furthermore, the organisation uses continuous IQ management such as IQ threats management, business process for IQ improvement, develop IQ management and IQ management improvement. The organisation has strict governance of IQ policies, IQ benchmarks, IQ planning, IQ Audit and provides accountability and rewards. In addition, organisation B considered IQ dimensions, such as AIS adoption processes, by using the IQ dimensions to check all processes to ensure AIS performance and providing IT governance in the organisation.

Another case study organisation also had a group of personnel who indicate that:
"We're using IQ criteria to control all work process in our organisation. So our systems have been some problem but overall [we're] satisfied. We have been using IQ criteria including Availability, Compliance, Confidentiality, Effectiveness, Efficiency, Integrity, Reliability as business policy and objective. Do you think they are appropriate? I think they are appropriate but should improve to high work performance."

Accounting Manager and director of IT (CompanyE)

Company $\mathrm{E}$ has controls embedded in business processes, IT processes and services, by adopting IQ criteria. In implementing AIS successfully, all stages have been concerned with information quality issues to improve the AIS adoption in the organisation. This approach covers strategy and tactics, and concerns the identification of the ways IT can best contribute to the achievement of the business objectives. In addition, the organisation has been using continuous IQ management such as Developing IQ implementation, Implementing IQ Project, and IQ management governance. Moreover, this company uses IQ criteria to support IT objectives and to measure them within the process employed to achieve the required performance.

\section{AIS Adoption Processes}

Fig 3 shows a summary of case studies' AIS Adoption process findings from multiple case studies by different types of business agricultural, financial, industrial, education and government. The selection of cases in this study was purposefully carried out in order to achieve theoretical and literal replication. The number of cases may depend on the purpose of research, available resources and constraints; in addition, the decision about the number of cases may be left to the individual researcher (Patton 1990). For the remaining factors, although to some extent conflicts still existed across cases, agreement seems greater than the differences. 


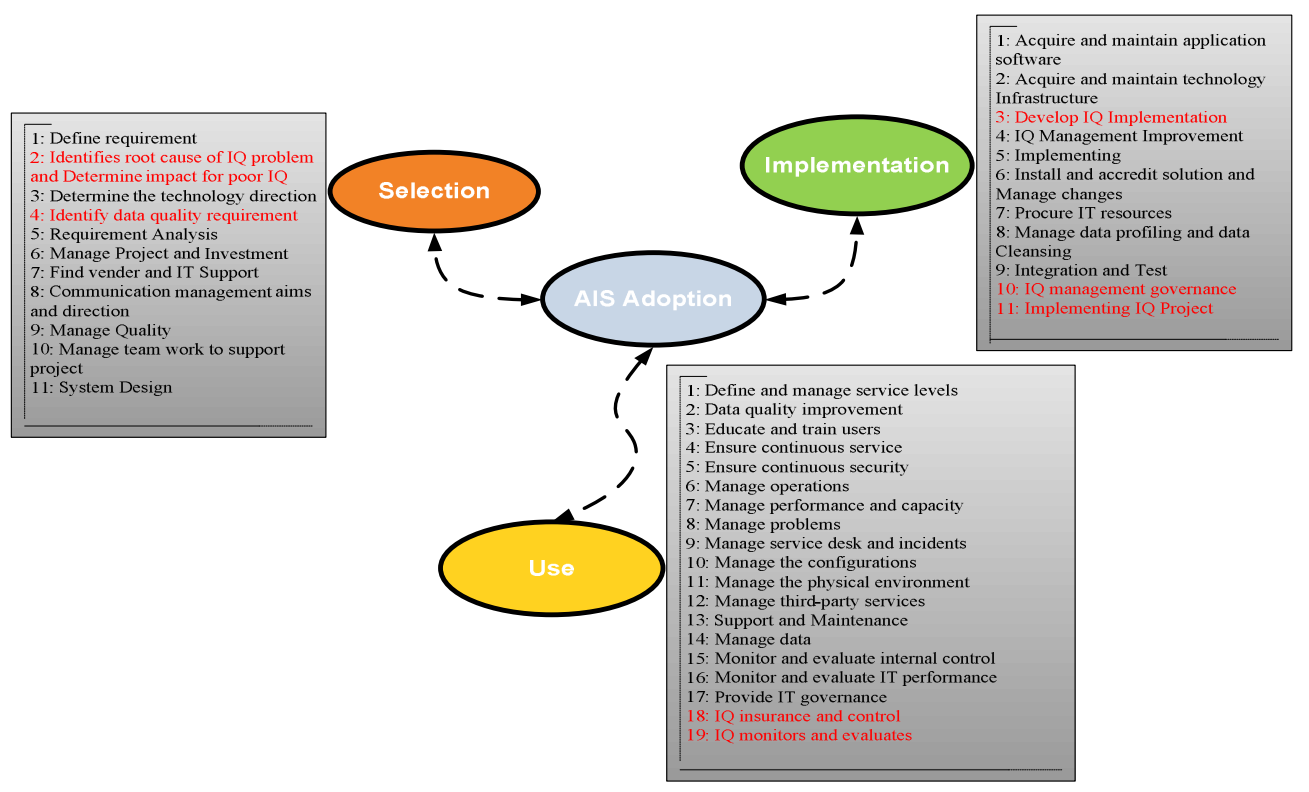

Fig 3. AIS Adoption Processes Model (Source: Developed by the authors)

\section{The Factors in Red Denote the New Factors that are Finding from Case Studies}

Fig 3 shows that adopting AIS involves using technology-adoption to support operations, strategic management, and decision-making in the firm. A wellmanaged and designed AIS adoption process can improve AIS performance and increase the efficiency of activities as well as help organisations to make profits by improving the quality and reducing the cost of products or services, sharing knowledge and improved decision-making (Romney, Marshall B 2009). The model reference framework defines 41 high-level control objectives for AIS adoption processes.

One of the interviewees identified the performance of an AIS adoption as most important in accounting activities. The director of the IT department noted that:

"We often are using 40 steps to manage and guidelines on how to develop new system depend on project and each system as development. Developing AIS includes 40 steps that include Define a requirement, Identifies root cause of IQ problem and determine impact of poor $I Q$, determine the technology direction, Identify data quality requirement, Requirement analysis, Manage Project and mange investment, Find vendor or IT Support, Communicate management aims and direction, Manage Quality, Manage team work to support project, System Design, Acquire and maintain application software, Acquire and maintain application maintain infrastructure, Develop IQ Implementation, IQ management Improvement, Implementing, Install and accredit solution and manage changes, Procure IT resources, Manage data profiling and data cleansing, Integration and Test, IQ management governance, Define and manage service levels, data quality improvement, Educate and train users, Ensure continuous service, Ensure system security, Manage operations, Manage performance and capacity, Manage problems, Manage service desk and incidents, Manage the configurations, Manage the physical environment, Manage third-party services, Support and Maintenance, Manage data, Monitor and evaluate internal control, Monitor and evaluate IT performance, Provide IT governance, IQ insurance and control, IQ monitors and evaluates. We have [to] check all processes before used accounting software upon IQ polices and also approval from board of organisation. We have been satisfy system this AIS system can help employee activity and work performance"

Director of IT department (Company B) 
Company B used AIS vendor for implementing its accounting systems and also adopted some accounting software modules as they could buy the software and then modify it themselves to use in the company.

Another case study organisation also had a large group of personnel who indicate that:

"This company seen as IQ has been important in acquire and implement AIS and using to control all stage adopting AIS process. Moreover, we have been defines 40 high-level control objectives for IT adoption processes that are described as Define a requirement, Identifies root cause of IQ problem and determine impact of poor $I Q$, determine the technology direction, Identify data quality requirement, Requirement analysis, Manage Project and mange investment, Find vendor or IT Support, Communicate management aims and direction, Manage Quality, Manage team work to support project, System Design, Acquire and maintain application software, Acquire and maintain application maintain infrastructure, Develop IQ Implementation, IQ management Improvement, Implementing, Install and accredit solution and manage changes, Manage data profiling and data cleansing, Integration and Test, IQ management governance, Implementing IQ Project, Define and manage service levels, data quality improvement, Educate and train users, Ensure continuous service, Ensure system security, Manage operations, Manage performance and capacity, Manage problems, Manage service desk and incidents, Manage the configurations, Manage the physical environment, Manage third-party services, Support and Maintenance, Manage data, Monitor and evaluate internal control, Monitor and evaluate IT performance, Provide IT governance, IQ insurance and control, IQ monitors and evaluates. We believe system can help improve our work. In addition, acquire and implement AIS relation to accounting information systems that important in an organisation, for it to become effective in business, decision making and growing business."

Director of IT audit division (Company E)
Company E employed wide implementation of a new accounting system supplied by the AIS vendor in order to implement accounting systems. Moreover, some modules can use their information systems to develop in-house software within the organisation, or companies may buy software and then modify it themselves to use in the company.

\section{Managing the IQ Dimensions into the AIS Adoption Process}

This research shows that, in developing accounting information systems, information quality management has the potential to influence decision making in each process of AIS adoption. Moreover, this study indicates that IQ dimensions have a positive relationship with AIS adoption processes. Table 1 shows ways of mapping the IQ dimensions into individual adoption stages using findings from the case studies. Within the adoption processes of AIS, AIS system selection which provides direction to solutions for the delivery of AIS system implementation is included. The AIS system implementation provides the solutions and passes them on, to be turned into services, receives the solutions, and makes them usable for end users. The AIS system use monitors for all processes to ensure that the direction is satisfied. In order to ensure that the AIS requirements for information quality are met, adequate control measures need to be defined, adopted and monitored over these resources.

\section{AIS System Selection}

The first stage is concerned with information quality issues to improve the AIS adoption in an organisation. This stage can help organisations to define a strategic IT plan. It covers strategy and tactics, and concerns the identification of the ways in which IT can best contribute to the achievement of the accounting objectives as business needs. Furthermore, organisations require defined requirements IQ criteria, requirements management, requirements analysis for 
control and to improve all processes of AIS adoption (shown in table1). They are also concerned about the root causes of IQ problems and determine the impact of poor IQ. Most importantly, the project manager is responsible for all IQ management efforts to improve quality of information in decision making for the acquired AIS system.

\section{AIS System Implementation}

The second stage helps an organisation to identify IT development. To realise an IT strategy, IT solutions need to be identified, developed or acquired, as well as implemented and integrated into the business processes. Moreover, changes in and maintenance of existing systems are covered by this stage to make sure the solutions continue to meet accounting objectives as business requirements. In addition, organisations must maintain continuous IQ management such as IQ risks management, IQ management cost advantage, accounts process for IQ improvement, IQ metrics management. Moreover, organisations must have strict governance of IQ roles, IQ benchmarks, IQ strategies, and the IQ Audit.

\section{AIS System Use}

Stage three addresses IT operations and is concerned with the actual delivery of required services. This incorporates the need to monitor operations, and addresses managing performance, monitoring of internal control, complaint regulatory procedures and providing governance. Distinguishing IQ dimensions in this way can help information producers and users understand the requirements for delivering high quality information by IQ insurance and control, IQ monitors and evaluations, and IQ governance. 
Table 1: Mapping IQ Dimension into Individual AIS Adoption Stage

\begin{tabular}{|c|c|c|c|c|c|c|c|c|c|c|c|c|c|c|c|c|}
\hline & \multicolumn{16}{|c|}{ IQ dimensions } \\
\hline & 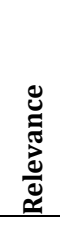 & 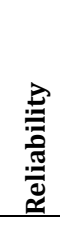 & 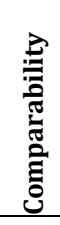 & 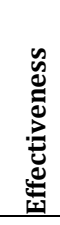 & 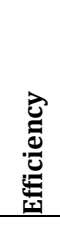 & 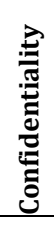 & 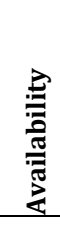 & 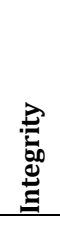 & : & 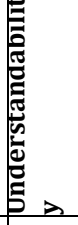 & 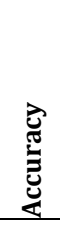 & 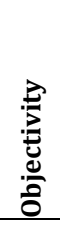 & 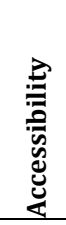 & 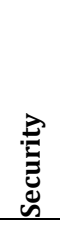 & 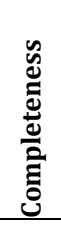 & $\stackrel{\Xi}{\Xi}$ \\
\hline \multicolumn{17}{|l|}{ AIS process } \\
\hline 1. Define requirement & & & & $\sqrt{ }$ & $\sqrt{ }$ & & & & & & & & & & & $\sqrt{ }$ \\
\hline $\begin{array}{l}\text { 2. Identifies root cause of IQ problem and } \\
\text { determine impact }\end{array}$ & & & & $\sqrt{ }$ & $\sqrt{ }$ & $\sqrt{ }$ & & $\sqrt{ }$ & & & & & & & & $\sqrt{ }$ \\
\hline 3. Determine the technological direction. & & & & $\sqrt{ }$ & $\sqrt{ }$ & & & & & & & & & & & \\
\hline 4. Identify data quality requirement & & & & $\sqrt{ }$ & $\sqrt{ }$ & & & & & & & & & & & \\
\hline 5. Requirement analysis & & $\sqrt{ }$ & & $\sqrt{ }$ & $\sqrt{ }$ & & & $\sqrt{ }$ & & & $\sqrt{ }$ & & & & $\sqrt{ }$ & $\sqrt{ }$ \\
\hline 6. Manage projects and manage Investment & & $\sqrt{ }$ & & $\sqrt{ }$ & $\sqrt{ }$ & & & & & & & & & & & \\
\hline 7. Find vendor and IT resources. & $\sqrt{ }$ & & & & & & $\sqrt{ }$ & & & $\sqrt{ }$ & $\sqrt{ }$ & $\sqrt{ }$ & & & & \\
\hline $\begin{array}{l}\text { 8.Communicate management aims and } \\
\text { direction. }\end{array}$ & & & & $\sqrt{ }$ & & & & & $\sqrt{ }$ & & & & & & & \\
\hline 9. Manage quality. & & $\sqrt{ }$ & & $\sqrt{ }$ & $\sqrt{ }$ & & & $\sqrt{ }$ & & & $\sqrt{ }$ & & & & $\sqrt{ }$ & $\sqrt{ }$ \\
\hline 10. Manage team work to support project & & & & $\sqrt{ }$ & $\sqrt{ }$ & & & & & & & & & & & \\
\hline 11. Design System & & & & $\sqrt{ }$ & $\sqrt{ }$ & & & & & $\sqrt{ }$ & & $\sqrt{ }$ & & $\sqrt{ }$ & & $\sqrt{ }$ \\
\hline $\begin{array}{l}\text { 12.Acquire and maintain application } \\
\text { software. }\end{array}$ & $\sqrt{ }$ & $\sqrt{ }$ & & $\sqrt{ }$ & $\sqrt{ }$ & & & $\sqrt{ }$ & & $\sqrt{ }$ & & & & & & $\sqrt{ }$ \\
\hline 13.Acquire and maintain infrastructure & $\sqrt{ }$ & $\sqrt{ }$ & & $\sqrt{ }$ & $\sqrt{ }$ & & & $\sqrt{ }$ & & $\sqrt{ }$ & & & & & & $\sqrt{ }$ \\
\hline 14.Develop IQ Implement & $\sqrt{ }$ & & & $\sqrt{ }$ & $\sqrt{ }$ & & & & & & $\sqrt{ }$ & & $\sqrt{ }$ & $\sqrt{ }$ & $\sqrt{ }$ & \\
\hline 15. IQ management improvement & $\sqrt{ }$ & & & $\sqrt{ }$ & $\sqrt{ }$ & & & & & & $\sqrt{ }$ & & $\sqrt{ }$ & $\sqrt{ }$ & $\sqrt{ }$ & \\
\hline 16. Implementing & $\sqrt{ }$ & & & $\sqrt{ }$ & $\sqrt{ }$ & & & & & & $\sqrt{ }$ & & $\sqrt{ }$ & $\sqrt{ }$ & $\sqrt{ }$ & \\
\hline $\begin{array}{l}\text { 17.Install and accredit solutions and } \\
\text { changes. }\end{array}$ & $\sqrt{ }$ & & & $\sqrt{ }$ & $\sqrt{ }$ & & $\sqrt{ }$ & $\sqrt{ }$ & & & & & $\sqrt{ }$ & & & $\sqrt{ }$ \\
\hline 18. Procure IT resources. & & & & $\sqrt{ }$ & $\sqrt{ }$ & & & & $\sqrt{ }$ & & & & & & & \\
\hline 19. Manage data profiling and data cleansing & $\sqrt{ }$ & $\sqrt{ }$ & $\sqrt{ }$ & & & & & & & $\sqrt{ }$ & $\sqrt{ }$ & & $\sqrt{ }$ & & $\sqrt{ }$ & \\
\hline 20.System integration and Testing & $\sqrt{ }$ & $\sqrt{ }$ & $\sqrt{ }$ & & & & & & & $\sqrt{ }$ & $\sqrt{ }$ & & $\sqrt{ }$ & & $\sqrt{ }$ & \\
\hline 21. Implement IQ Project & $\sqrt{ }$ & & & $\sqrt{ }$ & $\sqrt{ }$ & & & & & & $\sqrt{ }$ & & $\sqrt{ }$ & $\sqrt{ }$ & $\sqrt{ }$ & \\
\hline 22. IQ management governance & $\sqrt{ }$ & $\sqrt{ }$ & $\sqrt{ }$ & & & & & & & $\sqrt{ }$ & $\sqrt{ }$ & & $\sqrt{ }$ & & $\sqrt{ }$ & \\
\hline 23. Define and manage service levels. & & $\sqrt{ }$ & & $\sqrt{ }$ & $\sqrt{ }$ & $\sqrt{ }$ & $\sqrt{ }$ & $\sqrt{ }$ & $\sqrt{ }$ & & & & & & & \\
\hline 24. Data quality improvement & $\sqrt{ }$ & $\sqrt{ }$ & & & & & & $\sqrt{ }$ & & $\sqrt{ }$ & & & $\sqrt{ }$ & & & \\
\hline 25. Educate and train users. & & & & $\sqrt{ }$ & $\sqrt{ }$ & & & & & $\sqrt{ }$ & & & & & & \\
\hline 26. Ensure continuous service. & & & & $\sqrt{ }$ & $\sqrt{ }$ & & $\sqrt{ }$ & & & & & & & & & \\
\hline 27. Ensure systems security. & & $\sqrt{ }$ & & & & $\sqrt{ }$ & $\sqrt{ }$ & $\sqrt{ }$ & $\sqrt{ }$ & & & & $\sqrt{ }$ & $\sqrt{ }$ & & \\
\hline 28. Manage operations. & & $\sqrt{ }$ & & $\sqrt{ }$ & $\sqrt{ }$ & $\sqrt{ }$ & $\sqrt{ }$ & $\sqrt{ }$ & & & $\sqrt{ }$ & & $\sqrt{ }$ & & & \\
\hline 29. Manage performance and capacity. & $\sqrt{ }$ & & & $\sqrt{ }$ & $\sqrt{ }$ & & $\sqrt{ }$ & & & $\sqrt{ }$ & & & & & & \\
\hline 30. Manage problems. & & & & $\sqrt{ }$ & $\sqrt{ }$ & & $\sqrt{ }$ & & & $\sqrt{ }$ & & $\sqrt{ }$ & & & $\sqrt{ }$ & $\sqrt{ }$ \\
\hline 31. Manage service desk and incidents. & $\sqrt{ }$ & $\sqrt{ }$ & & $\sqrt{ }$ & $\sqrt{ }$ & & & & & & & & & & & \\
\hline 32. Manage the configurations. & & $\sqrt{ }$ & & $\sqrt{ }$ & $\sqrt{ }$ & & $\sqrt{ }$ & & & & & & & & & \\
\hline 33. Manage the physical environment. & & $\sqrt{ }$ & & & & & $\sqrt{ }$ & $\sqrt{ }$ & & & & & & & & \\
\hline 34. Manage third-party services. & & $\sqrt{ }$ & & $\sqrt{ }$ & $\sqrt{ }$ & $\sqrt{ }$ & $\sqrt{ }$ & $\sqrt{ }$ & $\sqrt{ }$ & & & & & & & \\
\hline 35. Support and Maintenance & $\sqrt{ }$ & & & $\sqrt{ }$ & $\sqrt{ }$ & & $\sqrt{ }$ & & & $\sqrt{ }$ & & & & & & \\
\hline 36. Manage data. & $\sqrt{ }$ & $\sqrt{ }$ & & & & & & $\sqrt{ }$ & & $\sqrt{ }$ & & & $\sqrt{ }$ & & & \\
\hline 37. Monitor and evaluate internal control. & $\sqrt{ }$ & $\sqrt{ }$ & $\sqrt{ }$ & $\sqrt{ }$ & $\sqrt{ }$ & $\sqrt{ }$ & $\sqrt{ }$ & $\sqrt{ }$ & $\sqrt{ }$ & $\sqrt{ }$ & & & & & & $\sqrt{ }$ \\
\hline 38. Monitor and evaluate IT performance. & $\sqrt{ }$ & $\sqrt{ }$ & & $\sqrt{ }$ & $\sqrt{ }$ & $\sqrt{ }$ & $\sqrt{ }$ & $\sqrt{ }$ & $\sqrt{ }$ & $\sqrt{ }$ & & $\sqrt{ }$ & & $\sqrt{ }$ & & \\
\hline 39. Provide IT governance & $\sqrt{ }$ & $\sqrt{ }$ & $\sqrt{ }$ & $\sqrt{ }$ & $\sqrt{ }$ & $\sqrt{ }$ & $\sqrt{ }$ & $\sqrt{ }$ & $\sqrt{ }$ & $\sqrt{ }$ & & & & & & \\
\hline 40. IQ insurance and control & & & & $\sqrt{ }$ & $\sqrt{ }$ & & $\sqrt{ }$ & & & & & & & & & \\
\hline 41. IQ monitors and evaluates & & $\sqrt{ }$ & & & & $\sqrt{ }$ & $\sqrt{ }$ & $\sqrt{ }$ & $\sqrt{ }$ & & & & $\sqrt{ }$ & $\sqrt{ }$ & & \\
\hline
\end{tabular}

(Source: Developed by the authors) 


\section{Discussion and Conclusions}

This analysis was done on the data of 44 respondents, from ten organisations within manufacturing firms in Thailand; data was collected by in-depth interviews which involved semi-structured interviews and unstructured interviews. This research provides empirical evidence that adopting AIS information from internal or external organisation requires recognition that information quality affects decisionmaking, suggesting that IQ dimensions should be considered in developing AIS in order to improve the effectiveness of AIS systems. This study investigates information quality dimensions in accounting information systems adoption. The framework measured IQ dimensions from sixteen dimensions including relevance, reliability, comparability, understandability, availability, effectiveness, efficiency, confidentiality, accessibility, integrity, compliance, accuracy, objectivity, security, completeness, and timeliness for adopting AIS. The level of importance of IQ dimensions was measured by a five point scale completed by the ten sample firms. The level of AIS adoption process defines 41 high-level control objectives as show in Fig 3. The overall results indicate that IQ dimensions have a positive relationship with AIS adoption processes. The evidence in this study suggests that an IQ criterion promotes AIS adoption process performance. Furthermore, IQ dimensions play a vital role in the process of AIS adoption. This evidence suggests that organisations should obtain knowledge of appropriate information quality dimensions for accounting information systems adoption to improve work performance as well as help organisations to make profits.

\section{References}

Avison, D. \& Myers, M. D. (2002). "Qualitative Research in Information Systems: A Reader," SAGE Publications.

Bovee, M. (2004). 'Empirical Validation of the Structure of an Information Quality
Model,' International Conference on Information Quality.

Choe, J.-M. (2004). "The Relationships among Management Accounting Information, Organizational Learning and Production Performance," Journal of Strategic Information Systems 13, 61-85.

Davila, T., Foster, G. \& Pearson, A. (2004). 'Management Accounting Systems Adoption Decisions: Evidence and Performance Implications from Startup Companies,'

Delone, W. H. \& McLean, E. R. (2003). "The DeLone and McLean Model of Information Systems Success: A Ten-Year Update," Journal of Management Information Systems 19, 9-30.

Gordon, L. A. \& Miller, D. (1976). "A Contingency Framework for the Design of Accounting Information Systems," Accounting, Organizations and Society 1, 59-69.

Ismail, N. A. (2009). Factors Influencing AIS Effectiveness among Manufacturing SMEs: Evidence from Malaysia. EJISDC 38, 1-19.

Ismail, N. A. \& King, M. (2005). "Firm Performance and AIS Alignment in Malaysian SMEs," International Journal of Accounting Information Systems 6, 241-259.

Kaplan, D., Krishnan, R., Padman, R. \& Peters, J. (1998). Assessing Data Quality in Accounting Information Systems, Communications of the ACM 41, 72-78.

Lee, Y. W., Strong, D. M., Kahn, B. K. \& Wang, R. Y. (2002). "AIMQ: A Methodology for Information Quality Assessment," Information \& Management 40, 133-146.

Malmi, T. (2001). "Balanced Scorecards in Finnish Companies: A Research Note," Management Accounting Research 12, 207 220.

McLaney, E. \& Atrill, P. (2005). 'Accounting: An Introduction,' (Financial Times/Prentice Hall). 
Michnik, J. \& Lo, M.-C. (2009). "The Assessment of the Information Quality with the Aid of Multiple Criteria Analysis," European Journal of Operational Research 195, 850-856.

Nelson, R. R. \& Todd, P. A. \& Wixom, B. H. (2005). "Antecedents of Information and System Quality: An Empirical Examination within the Context of Data Warehousing," Journal of Management Information Systems 21, 199-235.

Nicolaou, A. I. (2000). "A Contingency Model of Perceived Effectiveness in Accounting Information Systems Organizational Coordination and Control Effects," International Journal of Accounting Information Systems 1, 91-105.

Orlikowski, W. J. \& Baroudi, J. J. (1991). "Studying Information Technology in Organizations: Research Approaches And Assumptions," Information Systems Research 2, 1-28.

Patton, M. (1990). "Qualitative Evaluation and Research Methods," Sage Publications, Newbury Park

Redman, T. C. (1998). "The Impact of Poor Data Quality on the Typical Enterprise," Commun. ACM 41, 79-82.

Redman, T. C. (2008). Data Driven: Profiting from Your Most Important Business Asset.

Rom, A. \& Rohde, C. (2007). Management Accounting and Integrated Information Systems: A Literature Review, International Journal of Accounting Information Systems 8, 40-68.

Romney, M. B. \& Steinbart, P. J. (2009). 'Accounting Information Systems,' (Peason Prentice Hall).

Salaün, Y. \& Flores, K. (2001). "Information Quality: Meeting the Needs of the Consumer," International Journal of Information Management 21, 21-37. 